\title{
Segmenteel testisinfarct. A case report
}

\author{
Antal P. Oldenhof - Evelyne C. C. Cauberg - Erwin de Boer
}

Geaccepteerd op: 1 november 2021 / Published online: 7 december 2021

(C) The Author(s) 2021

Samenvatting In dit case report beschrijven wij een 36-jarige man, die zich op de Spoedeisende Hulp presenteerde met pijn in de rechterflank en rechter testis, die bleek te berusten op een segmenteel infarct van de rechter testis. Een segmenteel testisinfarct is een zeldzame oorzaak van acute scrotale pijn en is echografisch lastig te onderscheiden van een testistumor. De oorzaak is vaak idiopathisch. Predisponerende factoren zijn onder andere infectie, trauma en hematologische ziekten, zoals polycytemie. De behandeling is conservatief met pijnstillers, de pijn verdwijnt vaak spontaan.

Trefwoorden segmenteel testisinfarct $\cdot$ acute scrotale pijn

\section{Segmental testicular infarction. A case report}

Abstract In this case report, we describe a 36-year-old male who presented to the Emergency Department with right flank and testicular pain, which appeared to be due to a segmental infarction of the right testis. Segmental testicular infarction is a rare cause of acute scrotal pain and is difficult to distinguish from a testicular tumor on ultrasound. The cause is often idiopathic. Predisposing factors include infection, trauma and haematological diseases such as polycythaemia. Treatment is conservative with painkillers and the pain often disappears spontaneously.

Keywords segmental testicular infarction - acute scrotal pain

drs. A. P. Oldenhof $(\bowtie) \cdot$ dr. E. C. C. Cauberg

afdeling Urologie, Isala, Zwolle, Nederland

a.p.oldenhof@isala.nl

drs. E. de Boer

afdeling Radiologie, Isala, Zwolle, Nederland

\section{Introductie}

Een (segmenteel) testisinfarct is een zeldzame oorzaak van acute scrotale pijnklachten. Het komt voornamelijk voor tussen het tweede en vierde decennium. De diagnose is echografisch lastig te onderscheiden van een testistumor, maar het herkennen van een testisinfarct kan onnodige orchidectomieën voorkomen.

\section{Casus}

Een 36-jarige man, met in de voorgeschiedenis een prevesicale uretersteen rechts waarvoor ureterorenoscopie met steenbehandeling, diverticulitis en depressieve klachten, presenteerde zich op de Spoedeisende Hulp vanwege sinds drie dagen bestaande pijn in de onderrug en flank rechts en sinds één dag pijn in de rechter testis. Patiënt heeft geen mictieklachten en het ontlastingspatroon is onveranderd. Hij heeft geen koorts of koude rillingen, wel heeft hij tweemaal gebraakt kort na het innemen van opiaten. De overige tractusanamnese is niet bijdragend. Patiënt herkent de pijnklachten in de onderrug en flank van een eerdere niersteenaanval, toen had hij echter geen pijn in de rechter testis.

Bij het lichamelijk onderzoek zien wij een pijnlijke patiënt met een bloeddruk van 145/95 mmHg, een hartslag van 86 slagen per minuut, een zuurstofsaturatie van $96 \%$ bij kamerlucht en een temperatuur van $37,2^{\circ} \mathrm{C}$. Het abdomen is behoudens diffuse drukpijn in de onderbuik zonder loslaatpijn niet afwijkend. Er is geen slagpijn in beide nierloges. Onderzoek van het scrotum toont geen roodheid, zwelling of hoogstand van de testis. De rechter testis is bij palpatie erg pijnlijk, waardoor betrouwbaar onderzoek niet goed mogelijk is. De linker testis is niet pijnlijk en voelt niet afwijkend aan. De cremasterreflex is beiderzijds aanwezig. Laboratoriumonderzoek toont een leuko- 


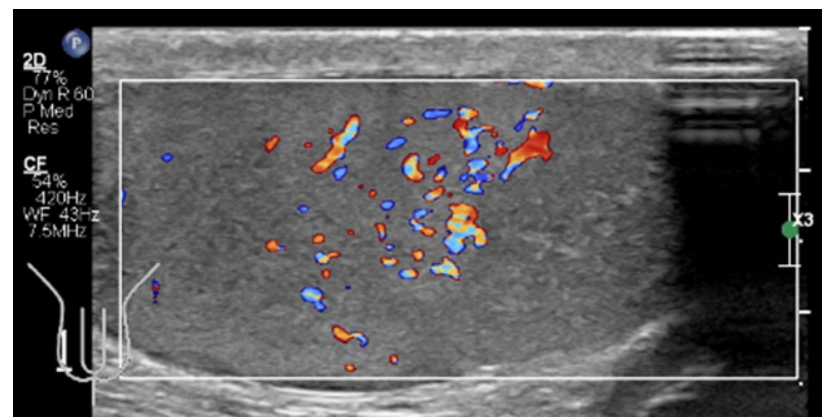

Figuur 1 Echodoppler van de rechter testis waarop afwezigheid van vascularisatie in de onderpool te zien is

cytose van $16,6 \times 10^{9} / 1$ met een CRP van $6 \mathrm{mg} / \mathrm{l}$. Overig laboratoriumonderzoek is niet afwijkend. In het urinesediment wordt een spoor erytrocyten gezien. Echo van de nieren en urinewegen tonen geen afwijkingen. Op een blanco CT-urinewegen wordt geen urolithiasis gezien en er is geen hydronefrose beiderzijds. Op de echodoppler van het scrotum wordt een echoarme onderpool van de rechter testis gezien zonder vascularisatie (fig. 1). Echografisch past het beeld niet bij een torsio testis of een epididymitis. De linker testis is niet afwijkend. Differentiaaldiagnostisch wordt gedacht aan een testistumor en een segmenteel testisinfarct. Patiënt wordt opgenomen in de kliniek ter observatie.

De volgende dag is de pijn in de onderbuik en flank niet meer aanwezig, de pijn in de rechter testis is iets afgenomen. De rechter testis voelt glad en vast-elastisch aan. Aanvullend laboratoriumonderzoek toont een leukocytose van $13,3 \times 10^{9} / 1$, het CRP is gestegen naar $25 \mathrm{mg} / \mathrm{l}$, het LDH bedraagt $295 \mathrm{U} / \mathrm{l}$, hCG $<0,1 \mathrm{U} / \mathrm{l}, \alpha$-1-foetoproteïne 2,5 U/ml. Na hernieuwde consultatie van de radioloog wordt de diagnose testistumor verworpen. Vanwege het mild gestegen CRP wordt pragmatisch levofloxacine $500 \mathrm{mg} 1 \mathrm{dd} 1$ gedurende 14 dagen voorgeschreven bij de differentiaaldiagnose 'beginnende orchitis' als onderliggende oorzaak voor een segmenteel infarct. Er werd een follow-up afgesproken middels herhaalde echodoppler na één week.

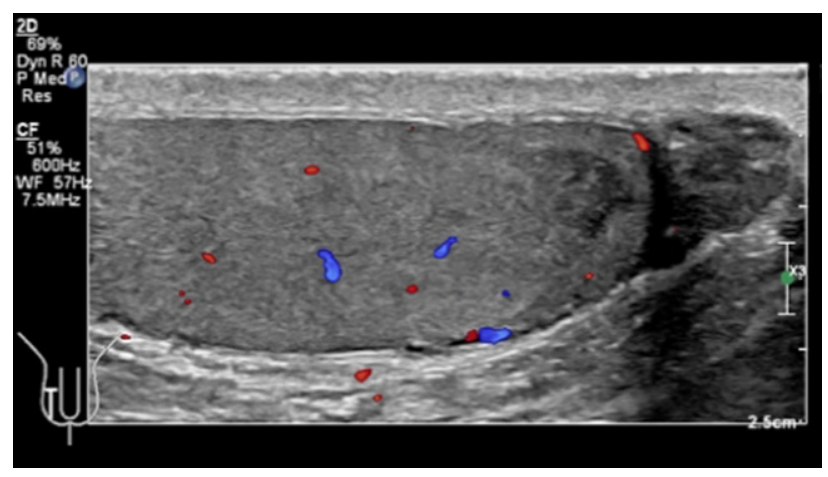

Figuur 2 Echodoppler één week na presentatie op de Spoedeisende Hulp, met inhomogeen aspect in de onderpool
Patiënt komt na één week terug op de polikliniek. Hij blijkt de antibiotica niet ingenomen te hebben. De pijn is volledig verdwenen, het lichamelijk onderzoek is niet afwijkend en een herhaalde echodoppler van het scrotum toont een echoarme onderpool van de rechter testis met een inhomogeen aspect van het parenchym lokaal, wat op eerdere echo niet werd gezien (fig. 2). Er is geen flow ter plaatse zichtbaar. Het beeld past goed bij de differentiaaldiagnose segmenteel testisinfarct.

\section{Discussie}

Een (segmenteel) testisinfarct is een zeldzaam verschijnsel en is wereldwijd minder dan 100 keer beschreven. Vaak wordt de diagnose gesteld op basis van histologie na orchidectomie, omdat een testisinfarct echografisch lastig te onderscheiden kan zijn van een testistumor [1]. Mannen presenteren zich vaak met acute scrotale pijn en in de differentiaaldiagnose staan torsio testis, orchitis/epididymitis en testistumor. Een testisinfarct komt voornamelijk voor onder 20- tot 40-jarigen. Predisponerende factoren zijn trauma, infectie, torsie-detorsie, operaties en hematologische ziekten, zoals sikkelcelziekte en polycythemie [2-4]. In de meeste gevallen blijft de etiologie echter onbekend en wordt een testisinfarct als idiopathisch geduid [5]. Zowel de linker als de rechter testis is even vaak aangedaan. In deze casus waren er geen predisponerende factoren aanwezig en is de oorzaak idiopathisch geduid.

Met echografie is een testisinfarct lastig te onderscheiden van een -tumor. Bij volledige afwezigheid van flow in de laesie (die soms wigvormig is) en een hyperemische rand op de echodoppler, moet de diagnose segmenteel testisinfarct worden overwogen, zeker wanneer de kliniek passend is bij de diagnose. Een MRI kan eveneens van toegevoegde waarde zijn voor het stellen van de diagnose. Bij een vermoeden van een testisinfarct is follow-up geïndiceerd middels herhaalde beeldvorming op korte termijn [2]. Uit een studie van Madaan et al. met 16 casus bleek dat bij het vermoeden van een segmenteel testisinfarct, follow-up een veilig alternatief was voor orchidectomie. In 11 van de 16 gevallen werd de echodoppler na 6 tot 12 weken herhaald en was daarop in negen gevallen regressie van de laesie te zien; in twee gevallen was de laesie onveranderd gebleven. De pijnklachten waren bij alle patiënten spontaan verdwenen [6]. Behandeling met anticoagulantia wordt niet aanbevolen; enig bewijs hiervoor ontbreekt [1].

Een normaal bèta-HCG en alfafoetoproteïne en een verhoogd LDH kunnen de diagnose testisinfarct ondersteunen. Echter, negatieve tumormarkers sluiten een testistumor niet geheel uit. 


\section{Conclusie}

De diagnose segmenteel testisinfarct hoort bij de differentiaaldiagnose van acute scrotale pijn te staan. Dit case report kan helpen bij het herkennen van deze diagnose, waardoor onnodige orchidectomieën voorkomen kunnen worden.

Open Access This article is distributed under the terms of the Creative Commons Attribution 4.0 International License (http://creativecommons.org/licenses/by/4.0/), which permits unrestricted use, distribution, and reproduction in any medium, provided you give appropriate credit to the original author(s) and the source, provide a link to the Creative Commons license, and indicate if changes were made.

\section{Literatuur}

1. Gkolezakis V, Petrolekas A, Koutsouri A, Ouranos V, Arapantoni P, Sidiropoulos P. Segmentaler hodeninfarkt. Urologe. 2018;57(8):947-50.

2. Cassidy FH, Ishioka KM, McMahon CJ, Chu P, Sakamoto K, Lee KS, et al. MR imaging of scrotal tumors and pseudotumors. Radiographics. 2010;30(3):665-83.
3. Zebari S, Huang DY, Wilkins CJ, Sidhu PS. Testicular acute segmental infarct following endovascular repair of a juxtarenalabdominal aortic aneurysm: casereportandliterature review. Urology. 2019;126:5-9.

4. West S, Karamsadkar S, Cross S. Segmental testicular infarction following nephrectomy. Radiol Case Rep. 2018;14(2):278-81.

5. Aquino M, Nghiem H, Jafri SZ, Schwartz J, Malhotra R, Amin M. Segmental testicular infarction. J Ultrasound Med. 2013;32(2):365-72.

6. Madaan S, Joniau S, Klockaerts K, DeWever L, Lerut E, Oyen R, et al. Segmental testicular infarction: conservative management is feasible and safe. Eur Urol. 2008;53(2):441-5.

drs. Antal P. Oldenhof, arts-assistent urologie

dr. Evelyne C.C. Cauberg, uroloog

drs. Erwin de Boer, radioloog 